\title{
Novel conditionally immortalized human proximal tubule cell line expressing functional influx and efflux transporters
}

\author{
Martijn J. Wilmer • Moin A. Saleem • Rosalinde Masereeuw • Lan Ni • \\ Thea J. van der Velden • Frans G. Russel • Peter W. Mathieson • Leo A. Monnens • \\ Lambertus P. van den Heuvel • Elena N. Levtchenko
}

Received: 9 March 2009/Accepted: 9 September 2009/Published online: 10 November 2009

(C) The Author(s) 2009. This article is published with open access at Springerlink.com

\begin{abstract}
Reabsorption of filtered solutes from the glomerular filtrate and excretion of waste products and xenobiotics are the main functions of the renal proximal tubular (PT) epithelium. A human PT cell line expressing a range of functional transporters would help to augment current knowledge in renal physiology and pharmacology. We have established and characterized a conditionally immortalized PT epithelial cell line (ciPTEC) obtained by trans-
\end{abstract}

Cystinosis Research Foundation, Cystinosis Research Network and European Community's Seventh Framework Programme (FP7/20072013, grant agreement $n^{\circ} 201590$ ) are acknowledged for their financial support.

M. J. Wilmer $(\varangle) \cdot$ T. J. van der Velden • L. A. Monnens •

L. P. van den Heuvel $\cdot$ E. N. Levtchenko

Laboratory of Pediatrics and Neurology (656),

Radboud University Nijmegen Medical Center,

P.O. 9101, 6500 HB Nijmegen, The Netherlands

e-mail: m.wilmer@cukz.umcn.nl

M. A. Saleem $\cdot$ L. Ni $\cdot$ P. W. Mathieson

Academic Renal Unit, Southmead Hospital,

Bristol, UK

R. Masereeuw · F. G. Russel

Department of Pharmacology and Toxicology,

Radboud University Nijmegen Medical Centre,

Nijmegen Centre for Molecular Life Sciences,

Nijmegen, The Netherlands

\section{A. Monnens}

Department of Physiology,

Radboud University Nijmegen Medical Centre,

Nijmegen Centre for Molecular Life Sciences,

Nijmegen, The Netherlands

E. N. Levtchenko

Department of Pediatrics, University Hospitals Leuven,

Leuven, Belgium fecting and subcloning cells exfoliated in the urine of a healthy volunteer. The PT origin of this line has been confirmed morphologically and by the expression of aminopeptidase $\mathrm{N}$, zona occludens 1, aquaporin 1, dipeptidyl peptidase IV and multidrug resistance protein 4 together with alkaline phosphatase activity. ciPTEC assembles in a tight monolayer with limited diffusion of inulin-fluorescein-isothiocyanate. Concentration and timedependent reabsorption of albumin via endocytosis has been demonstrated, together with sodium-dependent phosphate uptake. The expression and activity of apical efflux transporter p-glycoprotein and of baso-lateral influx transporter organic cation transporter 2 have been shown in ciPTEC. This established human ciPTEC expressing multiple endogenous organic ion transporters mimicking renal reabsorption and excretion represents a powerful tool for future in vitro transport studies in pharmacology and physiology.

Keywords Proximal tubule cell - Albumin endocytosis .

Phosphate transport - Organic cation transport .

P-glycoprotein · Human

\section{Introduction}

In the kidney, the proximal tubular (PT) epithelium is responsible for reabsorption of filtered solutes and excretion of waste products and xenobiotics. Numerous solutes, such as phosphate, urate and amino acids, are filtered in the glomerulus and reabsorbed in the proximal tubules by active sodium-coupled transport, driven by an electrochemical gradient (Madsen et al. 2008). Other compounds of the glomerular filtrate, such as albumin and low-molecular-weight proteins, are reabsorbed by 
receptor-mediated endocytosis (Gekle 2005). The excretion of metabolic waste products or drugs is facilitated by multiple organic ion transporters mediating uptake from blood at the basolateral membrane and efflux across the apical membrane of PT epithelial cells (PTEC; Russel et al. 2002).

The function and regulation of these transport systems is the subject of physiological and pharmacological research and requires a suitable in vitro cell model. In the last two decades, a variety of human and animal renal tubular cell lines have been used for this purpose (recently reviewed by Bens and Vandewalle 2008). Currently available human PTEC have variable characteristics or express only a few transporters, such as the commercially available HK-2 cell line obtained from renal cortex and transfected with recombinant HPV16 E6/E7 genes (Ryan et al. 1994; Racusen et al. 1995). On the other hand, primary PTEC, isolated from either human or animal kidney material, can only yield a limited amount of material, as proliferation stops after a few passages and the cells dedifferentiate (Brown et al. 2008; Terryn et al. 2007; Weiland et al. 2007). The development of a human cell model with PT characteristics, including multiple influx and efflux transporters, would be useful to extend our current knowledge of renal solute reabsorption and drug excretion.

To overcome the limited availability of functional human PTEC, the combination of culturing exfoliated cells from human urine followed by immortalization steps can be applied (Racusen et al. 1997; Wilmer et al. 2005). Infection by using both temperature-sensitive mutant U19tsA58 of SV40 large T antigen (SV40T) and the essential catalytic subunit of human telomerase (hTERT) has recently proven to be effective for the development of conditionally immortalized podocytes and human glomerular endothelial cells and for the immortalization of human fibroblasts (O'Hare et al. 2001; Saleem et al. 2002; Satchell et al. 2006). Transfection with SV40T allows cells to proliferate at the permissive low temperature of $33^{\circ} \mathrm{C}$, whereas the inactivation of the large $\mathrm{T}$ antigen at $37^{\circ} \mathrm{C}$ results in minor changes in gene expression (Stamps et al. 1994). The hTERT vector expresses telomerase activity to maintain telomere length, preventing the occurrence of replicative senescence (Bodnar et al. 1998).

Using a non-invasive technique of obtaining renal material from urine, we have developed conditionally immortalized human PTEC (ciPTEC) from a healthy volunteer. This cell line can be maintained for at least 45 passages and presents PT characteristics when cultured at the non-permissive temperature of $37^{\circ} \mathrm{C}$ for 10 days. The uptake of albumin and phosphate and the activities of the ATP-binding cassette $(\mathrm{ABC})$ transporter P-glycoprotein $(\mathrm{Pgp} / \mathrm{MDR} 1 / A B C B 1)$ and organic cation transporter 2 (OCT2, SLC22A2) are demonstrated.

\section{Materials and methods}

Primary cell culture

Primary cells were cultured as described previously by collecting mid-stream urine. Informed consent was obtained from the parents of healthy volunteers with no clinical history of renal disease, nor with any other chronic disease. Urine sediment was transferred to supplemented DMEMHAM's F12 medium (Lonza, Basel, Switzerland) and cultured at $37^{\circ} \mathrm{C}, 5 \% \mathrm{CO}_{2}$ (Wilmer et al. 2005).

Immortalization and subcloning

Primary cells were infected with SV40T and hTERT vectors containing respectively geneticin (G418) or hygromycin resistance as described before (O'Hare et al. 2001; Satchell et al. 2006). Subconfluent cell layers were transferred to $33^{\circ} \mathrm{C}$ and selected by using G418 (400 $\mu \mathrm{g} / \mathrm{ml}$; Sigma-Aldrich) and hygromycin B (25 $\mu \mathrm{g} / \mathrm{ml}$; Sigma-Aldrich) for 10 days. To obtain a homogeneous cell culture, cells were subcloned by using irradiated NIH 3T3 fibroblast as non-dividing feeder cells (Saleem et al. 2002). After being cultured for 2 weeks at $33^{\circ} \mathrm{C}$, single cell clones were visible and picked by using cloning discs drained in trypsin/EDTA. For the following experiments, cells were cultured at $33^{\circ} \mathrm{C}$ to $70 \%$ confluency, followed by maturation for 10 days at $37^{\circ} \mathrm{C}$ during which the cells formed a confluent monolayer. Propagation of cells was maintained by reseeding the cells at a dilution of 1:3 to $1: 6$ at $33^{\circ} \mathrm{C}$. Experimental procedures were performed on the cloned cells between passages 15 and 40 .

Morphology of ciPTEC was investigated by using phasecontrast microscopy. Additionally, cells cultured for 10 days at $37^{\circ} \mathrm{C}$ were scraped off flask by using a rubber policeman and embedded in paraffin for electron-microscopical analysis.

\section{Characterization of ciPTEC}

To investigate the epithelial origin of cells, confluent monolayers were fixed by using $2 \%$ paraformaldehyde, permeabilized in phosphate-buffered saline (PBS)-Tween $(0.1 \%)$ and incubated with antibodies against the tight junction protein, zona occludens 1 (ZO-1; 1:25 dilution; Zymed Laboratories, South San Francisco, Calif., USA). Following treatment with secondary goat-anti-rabbitAlexa488 conjugate (DAKO, Glostrup, Denmark) and 4,6-diamidino-2-phenylindole (DAPI, Molecular Probes, Invitrogen) to stain nuclei, cells were analysed by immuno-fluorescence microscopy. The presence of the brush-border membrane protein aminopeptidase $\mathrm{N}$ was detected by using mouse-anti-human CD13-fluoresceinisothiocyanate (FITC) antibody (DAKO) and endothelial marker CD31-FITC (DAKO) as described previously 
(Wilmer et al. 2005). Additionally, a sample of stained cells was transferred to a glass slide by cyto-spin $(1000 \mathrm{~g}$, $10 \mathrm{~min}$ ) and analysed by immuno-fluorescence microscopy. Alkaline phosphatase activity was determined in at least three independent experiments by using the BM Chemiluminescence ELISA substrate (AP) kit (Roche Diagnostics, Mannheim, Germany) as described previously (Wilmer et al. 2005). Values were compared with the HK-2 cell line as a positive control using shrimp alaline phosphate as standards and expressed as mean $\pm \mathrm{SE}$.

To investigate whether the monolayers assembled sufficiently tightly for transport studies, ciPTEC was cultured on Transwell-Clear polyester membranes (Corning Costar, Cambridge, Mass., USA) for 10 days at $37^{\circ} \mathrm{C}$. Both apical and basal compartments were washed in HEPES-TRIS buffer (10 mM HEPES-TRIS, $132 \mathrm{mM} \mathrm{NaCl}, 4.2 \mathrm{mM} \mathrm{KCl}$, $1 \mathrm{mM} \mathrm{CaCl} 2,1 \mathrm{mM} \mathrm{MgCl} 2,5.5 \mathrm{mM}$ D-glucose, $\mathrm{pH}$ 7.4), prior to the addition of $0.1 \mathrm{mg} / \mathrm{ml}$ inulin-FITC (SigmaAldrich) to the apical compartment. Inulin-FITC diffusion through the monolayer was monitored for $2 \mathrm{~h}$ by sampling $100 \mu \mathrm{l}$ apical and basal compartments and by measuring fluorescence at $485 \mathrm{~nm}$ with emission at $535 \mathrm{~nm}$. Data were expressed as mean $\pm \mathrm{SE}$.

Polyacrylamide gel electrophoresis and Western blotting

Cellular homogenates of cells cultured for various days at $37^{\circ} \mathrm{C}$ were made by scraping cells off $75-\mathrm{cm}^{2}$ tissue culture flask by using a rubber policeman and lysing them in $400 \mu 1$ RIPA buffer containing 1\% Igepal CA630, $0.5 \% \mathrm{Na}-$ deoxycholate, $0.1 \%$ SDS, $0.01 \%$ phenylmethane sulphonylfluoride, $3 \%$ aprotinin and $1 \mathrm{mM}$ Na-orthovanadate. Expression of SV40T antigen in cell homogenates was analysed by Western blotting using reduced $12 \%$ sodium dodecyl sulphate polyacrylamide gel electrophoresis (SDS-PAGE) and transference onto a polyvinylidene difluoride membrane (Immobilon; Millipore, Bedford, Mass., USA). Membranes were incubated with SV40T antibody (1:400 dilution; Santa Cruz Biotechnology, Santa Cruz, Calif., USA) and anti-D-glyceraldehyde-3-phosphate dehydrogenase (1:5000 dilution; Abcam, Cambridge, UK) as a house-keeping antigen, followed by incubation with goat-anti-mouse-horseradish peroxidase (HRP) conjugate (DAKO) and visualization by using Pierce ECL Western blotting substrate (Thermo Fisher Scientific, Waltham, Mass., USA).

Cellular homogenates matured for 10 days at $37^{\circ} \mathrm{C}$ were analysed as described above by $6 \%$ or $12 \%$ SDS-PAGE as indicated, with the following antibodies: rabbit antiaquaporin 1 (AQP1; 1:4000; 12\%; Chemicon International, Millipore), rabbit anti-OCT2 (1:500; 12\%, Alpha Diagnostics, San Antonio, Tex., USA), rabbit anti-CD26 (dipeptidyl peptidase IV [dpp-IV]; 1:200, 12\%; Santa Cruz Biotech- nology), rabbit anti-multidrug resistance protein 4 (van Aubel et al. 2002; MRP4, ABCC4; 1:5000; 6\%), mouse anti-Pgp (1:200; 6\%; Dako) goat-anti-mouse-HRP conjugate (DAKO) and goat-anti-rabbit-HRP conjugate (DAKO). Human kidney homogenate in RIPA buffer was used as a control.

\section{Albumin uptake by endocytosis}

The ability of ciPTEC to reabsorb albumin was investigated by the incubation of confluent monolayers in 24-well plates with $50 \mu \mathrm{g} / \mathrm{ml}$ bovine serum albumin (BSA)-FITC (SigmaAldrich) for $30 \mathrm{~min}$ at $37^{\circ} \mathrm{C}$ unless described otherwise. Uptake was arrested by using ice-cold PBS and cells were detached by using trypsin, fixed by paraformaldehyde $(0.5 \%)$ in PBS and analysed by flow cytometry or immuno-fluorescence microscopy. Concentration- and temperature-dependent uptake was investigated over a concentration range of BSA-FITC $(0,3.7,11,33,100$, $300 \mu \mathrm{g} / \mathrm{ml}$ ) at $37^{\circ} \mathrm{C}$ and on ice for $30 \mathrm{~min}$. Uptake inhibition was studied in three independent experiments by incubating the cells with BSA-FITC $(50 \mu \mathrm{g} / \mathrm{ml})$ in addition to excess unlabelled BSA $(10 \mathrm{mg} / \mathrm{ml})$ or recombinant receptor-associated protein (RAP; $1 \mu \mathrm{M}$ ), which was a kind gift of Dr. M. Nielsen (University of Aarhus, Denmark). Uptake inhibition by RAP was further examined by using a dilution range of RAP. BSA uptake in saturation experiments were plotted as mean fluorescence intensity and, in inhibition experiments, as mean $( \pm \mathrm{SE})$ percentage uptake compared with the control condition.

\section{Sodium-dependent phosphate uptake}

Phosphate uptake was performed in confluent monolayers with ${ }^{32} \mathrm{PO}_{4}$ (Perkin Elmer, Waltham, Mass., USA) as described earlier (Malmstrom et al. 1988). Cells cultured for 10 days at $37^{\circ} \mathrm{C}$ were incubated with $0.2 \mathrm{mM} \mathrm{KH}_{2} \mathrm{PO}_{4}$ $(10 \mu \mathrm{Ci} / \mathrm{ml})$ for $5 \mathrm{~min}$ in four independent experiments, in the presence of $137 \mathrm{mM}$ sodium salt or $137 \mathrm{mM} \mathrm{N}$-methylD-glucamine to study sodium-dependent transport. Additionally, time-dependent $(0.5,1,2,5,10,15,30$ or $60 \mathrm{~min})$ and concentration-dependent $(0.02,0.07,0.22,0.66$ or $2 \mathrm{mM} \mathrm{PO}_{4}$ ) uptake was studied. Data were expressed as mean $\pm \mathrm{SE}$.

\section{OCT2 activity}

Transport of xenobiotics across the basolateral membrane was investigated in ciPTEC by measuring the activity and expression of OCT2 by using a method adapted from Brown et al. (2008). Cells were grown on Transwell-Clear polyester membranes as described above. The activity of OCT2 was measured by incubating $1 \mu \mathrm{M}$ fluorescent OCT2 
substrate 4-(4-(dimethylamino)styryl)-N-methylpyridinium iodide (ASP; Invitrogen) in HEPES-TRIS buffer for $1 \mathrm{~min}$ at $37^{\circ} \mathrm{C}$ at the basal compartment. To inhibit OCT2mediated uptake, cells were exposed to $100 \mu \mathrm{M}$ tetrapentylammonium (TPA) at both apical and basal compartments for $10 \mathrm{~min}$ prior to uptake of ASP. Additionally, one set of experiments was performed at $4^{\circ} \mathrm{C}$. After incubation, transport was arrested by using $1 \mathrm{mM}$ ice-cold TPA. Cells were homogenized in $250 \mu \mathrm{l}$ HEPES-TRIS-Triton $(0.1 \%)$ buffer for $30 \mathrm{~min}$, followed by the analysis of fluorescence intensity (excitation $450 \mathrm{~nm}$, emission $642 \mathrm{~nm}$ ) by using a Victor3 Multiplate Reader (Perkin Elmer). Data were expressed as mean $\pm \mathrm{SE}$.

\section{Pgp activity}

The activity of the ABC efflux transporter Pgp was assessed by measuring the accumulation of calcein as described before (van de Water et al. 2007). Briefly, matured cells were incubated in two independent experiments for $1 \mathrm{~h}$ at $37^{\circ} \mathrm{C}$ with the lipophylic non-fluorescent Pgp substrate calcein-AM (Invitrogen) in the presence or absence of inhibitor PSC-833, which was a kind gift from Novartis Pharma (Basel, Switzerland). Intracellularly, calcein-AM is metabolized by esterase activity to fluorescent calcein. Fluorescence of cell lysates was measured at $488 \mathrm{~nm}$ with emission at $518 \mathrm{~nm}$. Fluorescence was expressed as mean $\pm \mathrm{SE}$.

\section{Statistical analysis}

Michaelis-Menten curve-fitting for the calculation of $\mathrm{K}_{\mathrm{m}}$ and $\mathrm{V}_{\max }$ values was performed by non-linear regression analysis with GraphPad Prism 4.03 software. Differences in substrate transport in the presence or absence of inhibitors or unlabelled analogues were assessed by a paired Student's $t$-test.

\section{Results}

Cell culture and morphology

Approximately $10 \%$ of the 38 collected mid-stream urine sediments from 31 healthy volunteers contained viable cells with the ability to proliferate into single cell colonies. Primary cultures showed heterogeneous morphology (Fig. 1a). Cell cultures infected with SV40T and hTERT were antibiotic-resistant to hygromycin $\mathrm{B}$ and geneticin (G418), indicating successful immortalization. Antibiotic resistance was maintained in ciPTEC for at least 40 passages suggesting that the expression of SV40T and hTERT consistently remained during proliferation at $33^{\circ} \mathrm{C}$. Proliferation was maintained at $33^{\circ} \mathrm{C}$ and cells transferred to $37^{\circ} \mathrm{C}$ at $70 \%$ confluency grew into confluent monolayers within 10 days, whereas SV40T antigen expression gradually decreased (Fig. 2). Subcloning of immortalized cells resulted in a cell culture with homogeneous cobblestone morphology (Fig. 1b). Analysis by electron microscopy showed moderate formation of microvilli and endocytic vesicles (Fig. 1c). Proliferation of clones could be maintained for at least 45 passages. Routinely, cell morphology was monitored by phase-contrast microscopy at each passage and showed no marked difference up to passage 40. To investigate the viability of the cells during maturation at $37^{\circ} \mathrm{C}$ for 10 days, a resazurin assay was performed (O'Brien et al. 2000; Yang and Balcarcel 2004) showing intact viability during the maturation stage (data not shown). Successfully immortalized cell lines obtained from two donors were subcloned, resulting in 15 and nine clones, respectively. These clones were characterized for the expression of aminopeptidase N, Pgp, AQP1 and dppIV (data not shown). Based on these results, one clone from one donor (female, 12 years) expressing the markers mentioned above was designated ciPTEC and selected for further investigation.
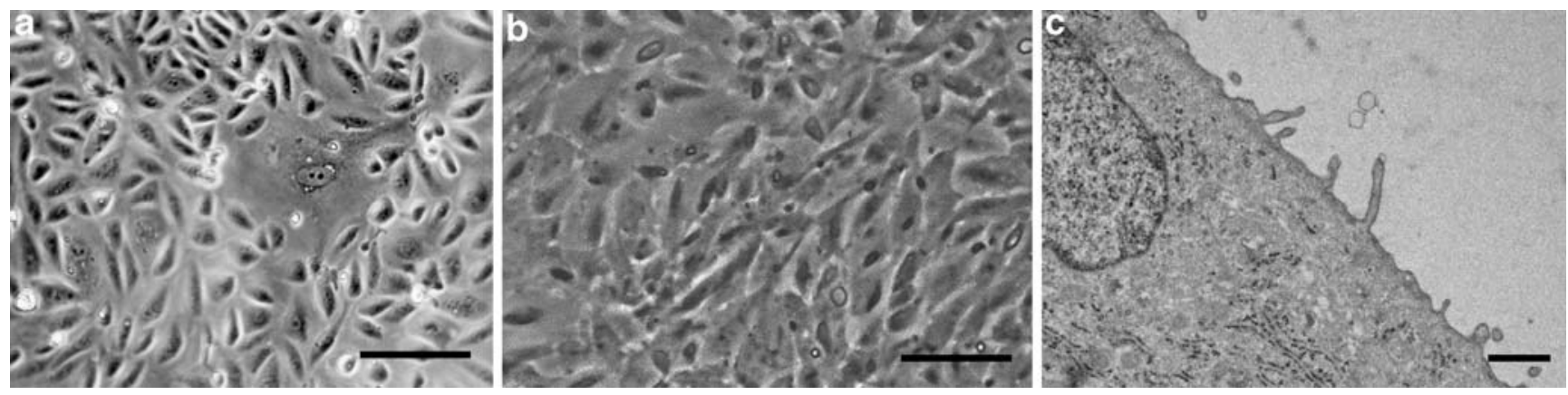

Fig. 1 Morphology of conditionally immortalized proximal tubular epithelial cell line (ciPTEC). a Representative phase-contrast image of primary cells with heterogeneous morphology before immortalization and subcloning. Bar $50 \mu \mathrm{m}$. b Phase-contrast image of confluent monolayers at passage 35 after immortalization, subcloning and maturation for 10 days at $37^{\circ} \mathrm{C}$. Bar $50 \mu \mathrm{m}$. c Electron micrograph of ciPTEC at passage 21 demonstrating microvilli. Bar $1 \mu \mathrm{m}$ 


\section{0 days $37 \mathrm{C}$}

\section{SV40T (94 kDa)}

\section{GAPDH (36kDa)}

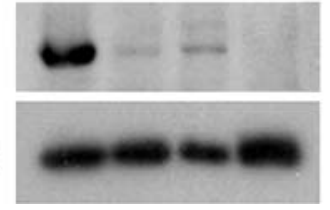

Fig. 2 Expression of SV40T in ciPTEC. Cell homogenates from ciPTEC cultured for various times at $37^{\circ} \mathrm{C}(37 \mathrm{C})$ were analysed for SV40T antigen expression by using Western blotting. House-keeping protein D-glyceraldehyde-3-phosphate dehydrogenase $(G A P D H)$ was used as the control

\section{Characterization of ciPTEC}

Since a mixture of cell types can be exfoliated in urine, a characterization study was performed after subcloning the cell line to confirm its PT origin (Dorrenhaus et al. 2000). At $37^{\circ} \mathrm{C}$, monolayers of the subclones expressed ZO-1 protein, indicating the epithelial origin of cells with development of tight junctions (Fig. 3a). Formation of tight monolayers was further supported by the inulin-FITC diffusion experiments. Cells grown on permeable filter supports assembled to a monolayer, with $13.2 \%( \pm 1.1)$ diffusion of inulin-FITC after a 2-h incubation at $37^{\circ} \mathrm{C}$. PT-specific brush-border membrane enzyme aminopeptidase $\mathrm{N}$ (CD13) was detected by using flow cytometry and immuno-fluorescence microscopy (Fig. 3b, c). The activity of brush-border membrane enzyme alkaline phosphatase was investigated and compared with its activity in HK-2 cell lines (ATCC; Manassas, Va., USA). In ciPTEC, the activity of alkaline phosphatase was $0.96 \pm 0.21$ and in HK-2 $0.59 \pm 0.03 \mathrm{mU} \mathrm{SAP} / \mathrm{mg}$ protein. Endothelial marker CD31 did not bind to ciPTEC (data not shown). CiPTEC could be clearly distinguished from the human podocyte cell line (Saleem et al. 2002) because of differences in morphology and the presence of $\mathrm{CD} 13$ antigen and alkaline phosphatase activity (Wilmer et al. 2005).

The presence of PT-specific transporters and enzymes AQP1, dpp-IV and MRP4 was demonstrated in cells cultured for 10 days at $37^{\circ} \mathrm{C}$ (Fig. 4). Cells originating from distal tubules or collecting ducts were excluded by the positive expression of AQP1 in ciPTEC (Nielsen et al. 1999). The variations in molecular size between ciPTEC and human kidney MRP4 were probably attributable to a difference in the glycosylation of this $\mathrm{ABC}$-transporter (El-Sheikh et al. 2008).

\section{Albumin uptake in ciPTEC}

The reabsorption of albumin was analysed by using FITClabelled bovine serum albumin (BSA-FITC) uptake in ciPTEC between passage number 20-25. The results indicated that uptake was concentration- and temperaturedependent, suggesting the active and specific transport of BSA in ciPTEC (Fig. 5a). Kinetic analysis of BSA-FITC uptake resulted in an apparent $\mathrm{K}_{\mathrm{m}}$ of $126 \mu \mathrm{g} / \mathrm{ml}$. To investigate the mechanism of BSA uptake, the localization of BSA-FITC was analysed and uptake was performed in the presence of RAP, a known inhibitor of albumin endocytosis by binding to multi-ligand receptor megalin (Zhai et al. 2000), or excess unlabelled BSA. The vesicular pattern of BSA-FITC indicated uptake via endocytic vesicles (Fig. 5b). Additionally, RAP inhibited the uptake of BSA-FITC in a concentration-dependent manner (Fig. 5c). BSA-FITC uptake was significantly inhibited in the presence of $1 \mu \mathrm{M}$ RAP $(P<0.05)$ or 200 -fold excess unlabelled FITC $(P<0.01)$ by $41 \%$ and $54 \%$, respectively (Fig. 5d).
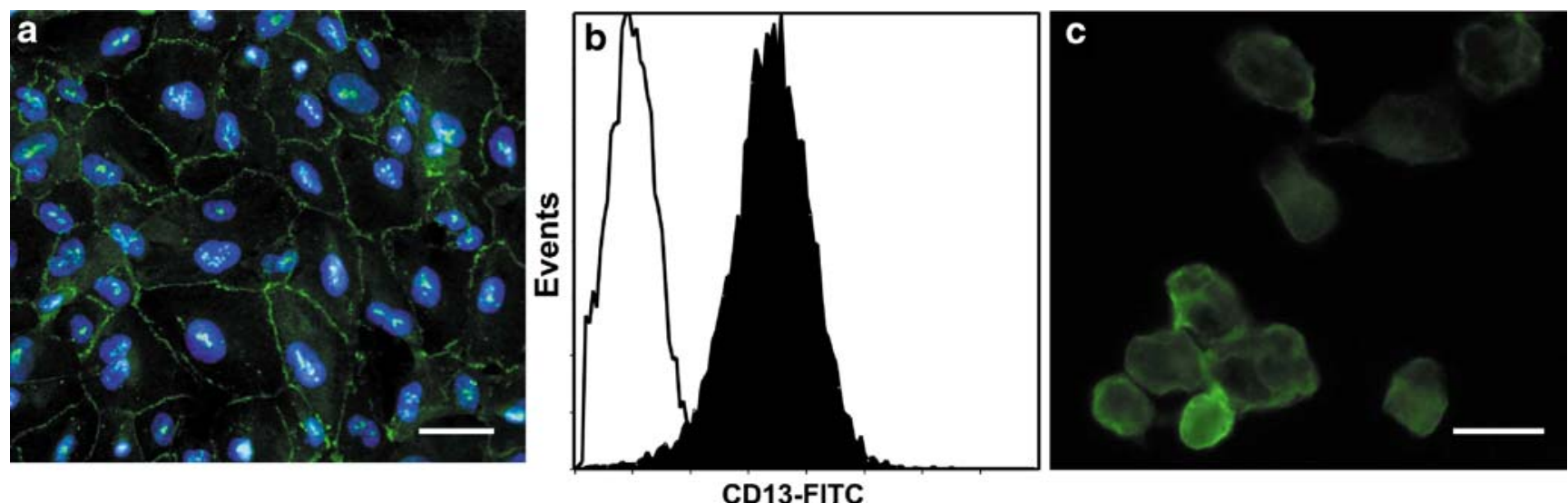

Fig. 3 Proximal tubular (PT) epithelial origin of ciPTEC. Expression of epithelial marker ZO-1 (green) was analysed (a) in confluent monolayers after 10 days of maturation at $37^{\circ} \mathrm{C}$ indicating the formation of tight junctions (blue DAPI nuclear staining). Aminopep- tidase $\mathrm{N}$ was detected by using incubation of ciPTEC with anti-CD13FITC and analysed (b) by flow cytometry (white histogram negative control, black histogram incubation with CD13-FITC) and (c) by immuno-fluorescence microscopy (green). Bars $20 \mu \mathrm{m}$ 
Fig. 4 Western blotting of ciPTEC. Expression of PT-specific proteins aquaporin-1 ( $A Q P 1)$, dipeptidyl peptidase IV (dppIV) (MRP4 (ABCC4)) in cell homopared with expression in human kidney homogenate (huKid) by Western blotting and multi resistant protein 4 genates of ciPTEC was com-

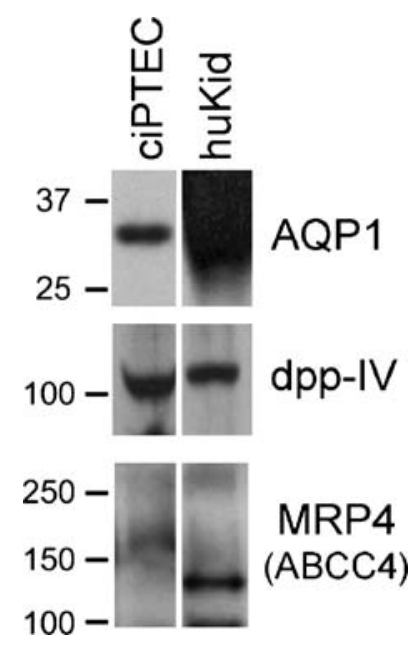

Sodium-dependent phosphate uptake

The uptake of phosphate in PTEC is mediated by the sodiumdependent transporters NaPi-IIa (SLC 34A1) and NaPi-IIc (SLC34A3; Forster et al. 2006). In the presented ciPTEC, the uptake of ${ }^{32} \mathrm{PO}_{4}$ was concentration and sodium-dependent (Fig. 6a). The maximum phosphate uptake rate (Vmax) was
$1717 \mathrm{pmol} / 24$ well per $5 \mathrm{~min}$ and an apparent $\mathrm{K}_{\mathrm{m}}$ of $0.12 \mathrm{mM}$ was calculated. In the absence of sodium, uptake was significantly decreased by approximately $86 \%$ $(P<0.001$; Fig. 6b). Phosphate uptake was performed at passage numbers ranging from 30 to 39 with comparable results, suggesting sodium-dependent phosphate uptake remained functional at higher passage numbers.

Organic cation transport activity

The ability of ciPTEC to transport xenobiotics was studied by the expression and activity of the basolateral transporter OCT2 and the apical efflux ABC-transporter Pgp. Western blotting of cell homogenates of ciPTEC cultured at $37^{\circ} \mathrm{C}$ clearly showed the presence of OCT2 (Fig. 7a) and Pgp (Fig. 8a). Expression of both transporters was confirmed by Western blotting in cell homogenates of passage number 40, indicating tubular characteristics remained over time. Basolateral exposure to ASP was internalized by ciPTEC cultured on supporting membranes. This transport could be significantly inhibited by OCT2 inhibitor TPA $(P<0.05)$ or when uptake was performed at $4^{\circ} \mathrm{C}(P<0.01)$ by respectively
Fig. 5 Albumin uptake in ciPTEC analysed by using BSAFITC. a Uptake of BSA is concentration- and temperaturedependent (black line at $37^{\circ} \mathrm{C}$, dashed line at $4^{\circ} \mathrm{C}$ ); data are expressed as means of duplicate experiments. b BSA-FITC (green) is located in intracellular vesicles (blue DAPI nuclear staining). Bar $10 \mu \mathrm{m}$. c Uptake of BSA-FITC $(50 \mu \mathrm{g} / \mathrm{ml})$ is inhibited by RAP in a concentration-dependent manner. Data are expressed as means of duplicate experiments. d Uptake is significantly inhibited by $1 \mu$ M RAP $(P<0.05$; grey bar $)$ or excess unlabelled BSA $(X S$ $B S A, 200$-fold; $P<0.01$; white bar). Data are means of three independent experiments $( \pm \mathrm{SE})$ and expressed as relative uptake compared with normal BSAFITC uptake
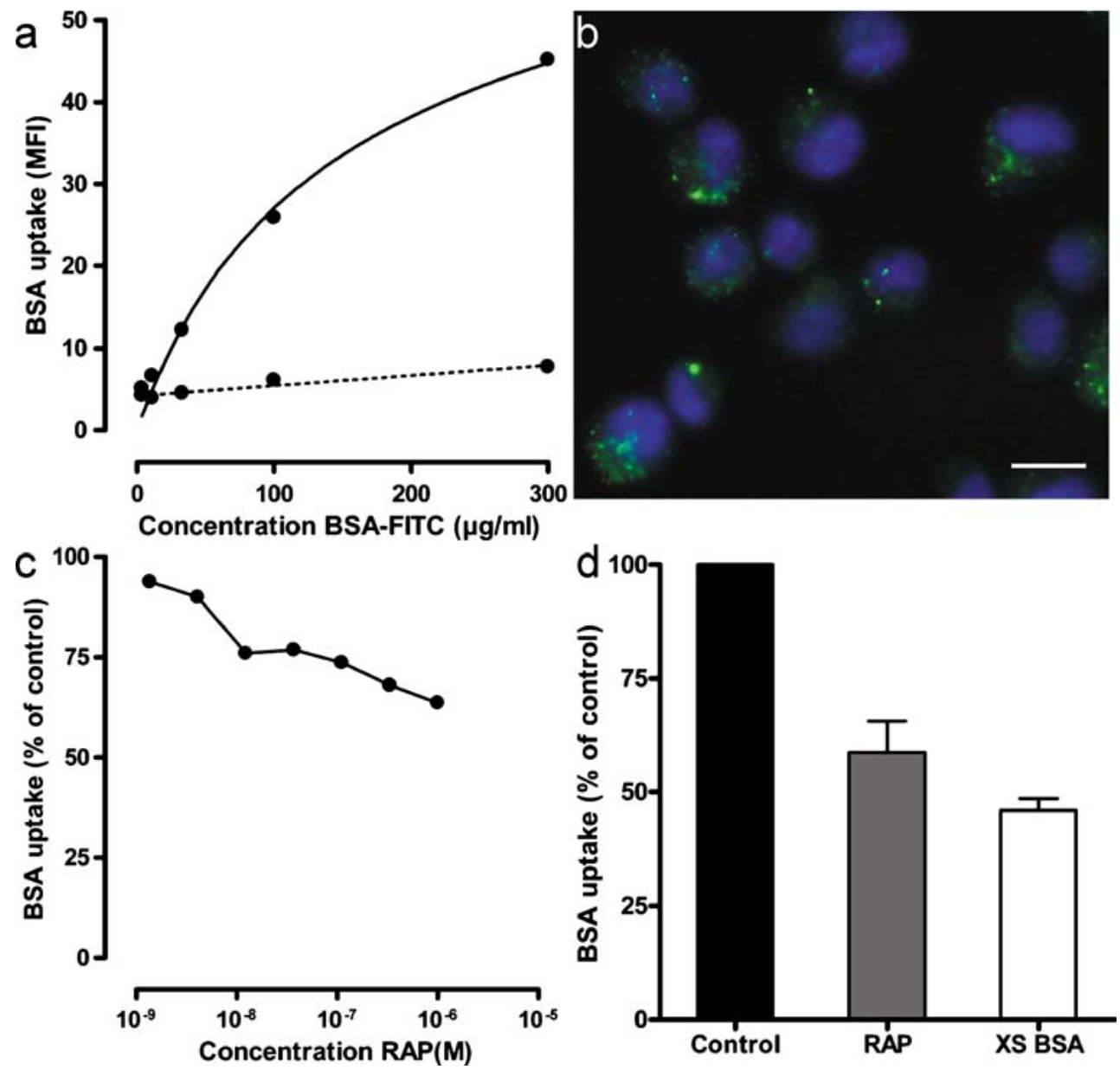


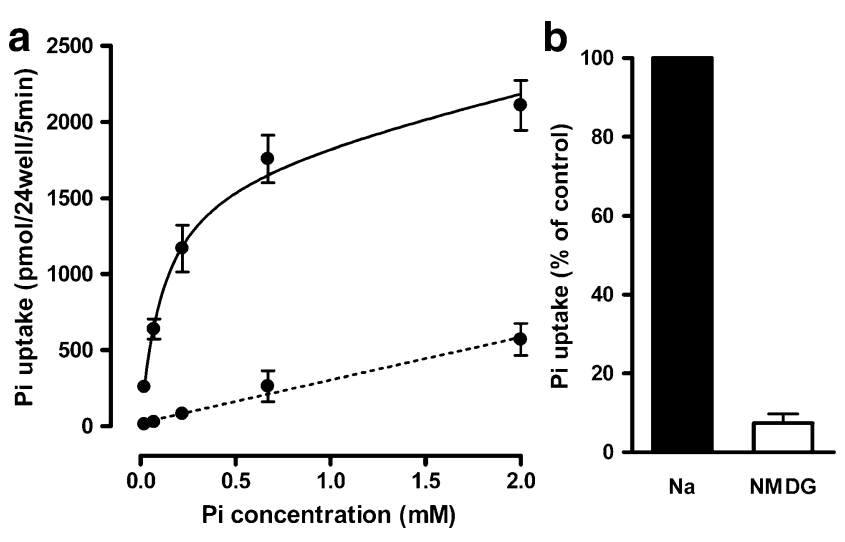

Fig. 6 Sodium-dependent phosphate uptake. In ciPTEC, uptake of ${ }^{32} \mathrm{PO}_{4}(\mathrm{Pi})$ was analysed in the presence and absence of sodium in four independent experiments. a Uptake of Pi was concentration-dependent and sodium-dependent (black line in presence of sodium, dashed line with N-methyl-D-glucamine as sodium replacement). b Uptake of $0.2 \mathrm{mM}$ Pi was significantly decreased $(P<0.001)$ in the absence of sodium (N-methyl-D-glucamine)

$36 \%$ and $30 \%$ (Fig. 7b). Significantly more intracellular fluorescent calcein accumulated when cells were incubated with PSC-833 (ratio 1.6; $P<0.001$; Fig. 8b), indicating Pgp-dependent transport activity in ciPTEC. To determine whether Pgp activity remained over time during proliferation, the calcein assay was performed in cells of up to passage number 39. This resulted in the active export of calcein, which could be inhibited by PSC-833 (ratio 2.3), indicating Pgp was functionally expressed at a high passage number.
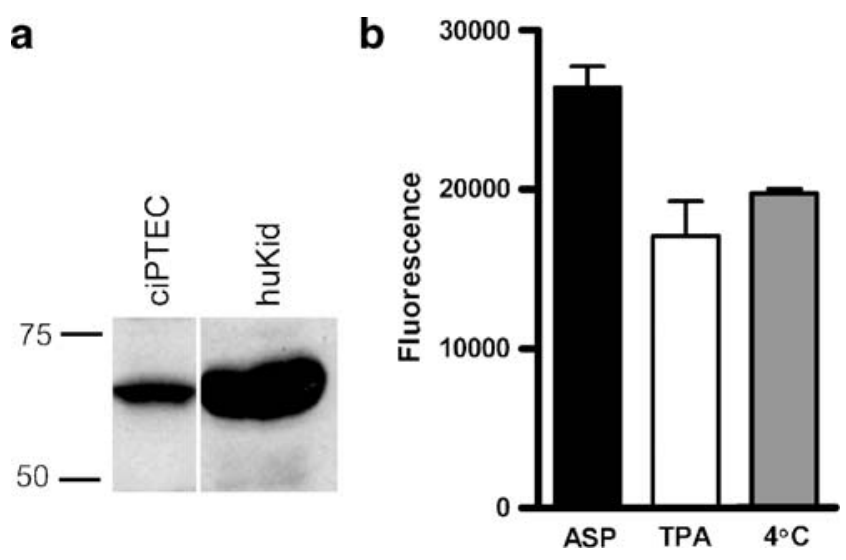

Fig. 7 Organic cation transporter 2 (OCT2) activity in ciPTEC. a Presence of OCT2 as shown by using Western blotting of ciPTEC homogenates (huKid human kidney homogenate as a control). b Activity of OCT2 analysed by measuring the fluorescence of transported 4-(4-(dimethylamino)styryl)-N-methylpyridinium iodide (ASP) in the absence (black bar) or presence (white bar) of OCT2 inhibitor tetrapentylammonium (TPA). Additionally, uptake was performed at $4^{\circ} \mathrm{C}$ (grey bar). Uptake was significantly decreased in ciPTEC in the presence of TPA $(P<0.05)$ or at $4^{\circ} \mathrm{C}(P<0.01)$. Data are expressed as means \pm SE of three experiments
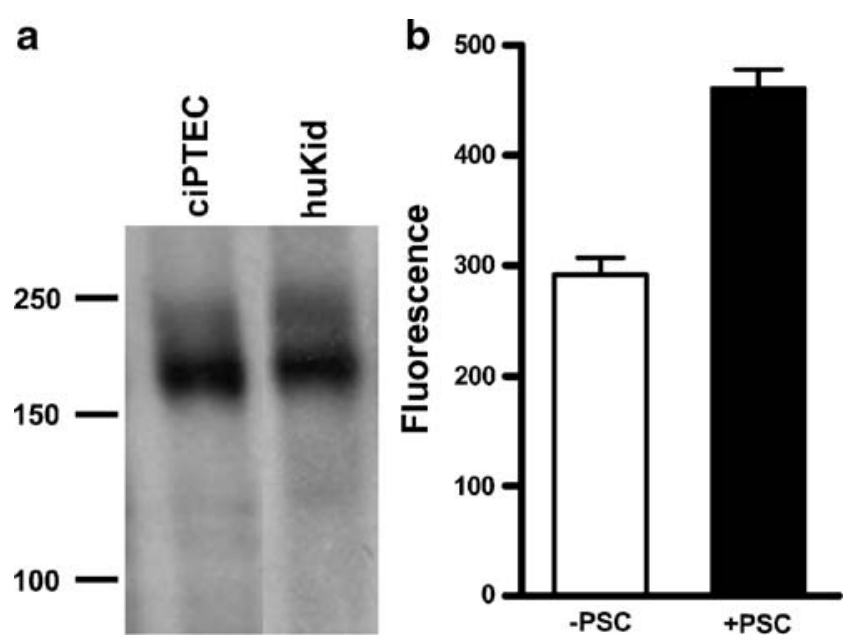

Fig. 8 P-glycoprotein (Pgp) activity in ciPTEC. a Presence of Pgp as shown by using Western blotting of ciPTEC homogenates (huKid human kidney homogenate as a control). b Activity of Pgp was analysed by measuring the fluorescence of accumulated calcein in the absence (white bar) or presence (black bar) of Pgp inhibitor PSC-833 (PSC). Accumulation was significantly increased in ciPTEC in presence of PSC-833 $(P<0.001)$. Data are expressed as means \pm SE of three experiments

\section{Discussion}

We have developed a human conditionally immortalized PT cell line from urine of a healthy volunteer; this line expresses transporters involved in renal reabsorption and excretion. The immortalization of non-invasively collected cells by using SV40T and hTERT vectors has enabled us to produce human cells maintaining PT characteristics and proliferating for at least 45 passages. Expression of SV40T decreases gradually in ciPTEC cultured for 10 days at $37^{\circ} \mathrm{C}$, minimizing the influence of the transfection on cellular metabolism. Subcloning improves the homogeneity of the cell line as is shown by the decrease in morphological variations, which possibly occur because of the exfoliation of various cell types originating from the renal-urinary tract into urine (Dorrenhaus et al. 2000).

For the culture of renal cells from urine, we have used the methodology described by Racusen et al. (1997) who have developed conditionally immortalized PTEC clones from the urine of two patients with nephropathic cystinosis, an inherited disorder of PT transport attributable to lysosomal cystine accumulation (Gahl et al. 2002). These cells represent a suitable model for studying the pathogenesis of cystinosis. Obviously, such studies require healthy control cells obtained by the same methodology as described in this study. The culturing of PTEC from control urine is hampered by the small amounts of viable exfoliated cells in the urine of healthy volunteers. In the present study, the success rate for culturing proliferating cells is approximately $10 \%$. Interestingly, only some urine 
samples from a few subjects contain viable PTEC with variable morphology.

The cells exfoliated in urine could be argued to be a less than ideal source for the establishment of a PTEC cell line, since cell damage could have resulted in their detachment from the tubular basement membrane. However, the detailed characterization of the ciPTEC presented here, including their viability, proliferation capacity, formation of a tight monolayer and preserved PT characteristics, indicates the feasibility of using urinary cells as a source for obtaining human renal material for in vitro research. Furthermore, the study of the pathogenesis of inherited PT disorders, which is often hampered by the limited availability of renal tissue, can be facilitated by collecting affected cells from the urine of these patients (Detrisac et al. 1983, 1984; Racusen et al. 1997).

In pharmacology and toxicology, the availability of a cell model of human origin expressing a broad range of functional transporters is of paramount importance. More specifically, the ciPTEC presented here is the first human cell line showing expression of MRP4, in concert with the expression and activity of OCT2 and Pgp. Probably because of different glycosylation, MRP4 in ciPTEC on Western blot shows a band of a different size from that of human kidney. We have therefore confirmed MRP4 expression by quantitative polymerase chain reaction after RNA isolation from ciPTEC. Together with the formation of a tight monolayer, as observed during the inulin diffusion experiments, these features make ciPTEC a valuable tool for the identification of substrates and inhibitors of renal drug excretion and the prediction of potential drug-drug interactions in pharmacological research. In addition to functional organic cation excretion, the human ciPTEC maintain sodium-dependent phosphate uptake and albumin endocytosis sensitive to inhibition by RAP. The apparent $\mathrm{Km}$ calculated for sodium-dependent phosphate transport in ciPTEC $(0.12 \mathrm{mM})$ is approximately one-third of the apical phosphate transport value demonstrated in opossum kidney $(\mathrm{OK})$ cells $(0.37 \mathrm{mM})$ (Reshkin et al. 1990). This suggests a higher affinity for phosphate in ciPTEC compared with currently available cell models.

The reabsorption of albumin by ciPTEC in this study is most likely receptor-mediated endocytosis transport, since it is sensitive to RAP inhibition and the intracellular vesicular pattern of BSA-FITC. Inhibition of BSA-FITC in ciPTEC is similar to the inhibition found earlier in OK cells (Zhai et al. 2000), whereas the apparent $\mathrm{Km}$ calculated for ciPTEC $(126 \mu \mathrm{g} / \mathrm{ml})$ is approximately six times higher than the value reported for OK cells $(20 \mu \mathrm{g} / \mathrm{ml}$; Gekle et al. 1996). Although this transport might be linked to the multiligand receptor megalin, we have been unable to identify this receptor by Western blot or by immunofluorescence techniques (data not shown; Birn and Christensen 2006).
This suggests the involvement of alternative albumin reabsorption mechanisms (Gekle 2005).

In conclusion, the present study introduces the first human cell line featuring functional sodium-dependent and endocytosis-mediated reabsorption together with the functional secretion capacity by Pgp and OCT2 and combined expression of MRP4. The ability of ciPTEC to proliferate for extended passages with maintained functional transport should allow standardized and high-throughput investigation of renal drug handling in pharmacological research.

Acknowledgements The authors are grateful for fruitful discussions of the present study with E.I. Christensen and to M. O'Hare for giving permission to use the SV40T construct. Technical assistance with the Pgp activity experiments by Janny G.P. Peters is gratefully acknowledged. We thank Raf Ponsaerts, Eva Sammels and Djalila Mekahli for their assistance in preparing the microscopic images.

Open Access This article is distributed under the terms of the Creative Commons Attribution Noncommercial License which permits any noncommercial use, distribution, and reproduction in any medium, provided the original author(s) and source are credited.

\section{References}

Bens M, Vandewalle A (2008) Cell models for studying renal physiology. Pflügers Arch 457:1-15

Birn H, Christensen EI (2006) Renal albumin absorption in physiology and pathology. Kidney Int 69:440-449

Bodnar AG, Ouellette M, Frolkis M, Holt SE, Chiu CP, Morin GB, Harley CB, Shay JW, Lichtsteiner S, Wright WE (1998) Extension of life-span by introduction of telomerase into normal human cells. Science 279:349-352

Brown CD, Sayer R, Windass AS, Haslam IS, De Broe ME, D'Haese PC, Verhulst A (2008) Characterisation of human tubular cell monolayers as a model of proximal tubular xenobiotic handling. Toxicol Appl Pharmacol 233:428-438

Detrisac CJ, Mayfield RK, Colwell JA, Garvin AJ, Sens DA (1983) In vitro culture of cells exfoliated in the urine by patients with diabetes mellitus. J Clin Invest 71:170-173

Detrisac CJ, Sens MA, Garvin AJ, Spicer SS, Sens DA (1984) Tissue culture of human kidney epithelial cells of proximal tubule origin. Kidney Int 25:383-390

Dorrenhaus A, Muller JI, Golka K, Jedrusik P, Schulze H, Follmann W (2000) Cultures of exfoliated epithelial cells from different locations of the human urinary tract and the renal tubular system. Arch Toxicol 74:618-626

El-Sheikh AA, van den Heuvel JJ, Krieger E, Russel FG, Koenderink JB (2008) Functional role of arginine 375 in transmembrane helix 6 of multidrug resistance protein 4 (MRP4/ABCC4). Mol Pharmacol 174:964-971

Forster IC, Hernando N, Biber J, Murer H (2006) Proximal tubular handling of phosphate: a molecular perspective. Kidney Int 70:1548-1559

Gahl WA, Thoene JG, Schneider JA (2002) Cystinosis. N Engl J Med 347:111-121

Gekle M (2005) Renal tubule albumin transport. Annu Rev Physiol 67:573-594

Gekle M, Mildenberger S, Freudinger R, Silbernagl S (1996) Functional characterization of albumin binding to the apical membrane of OK cells. Am J Physiol 271:F286-F291 
Madsen KM, Nielsen S, Tisher CC (2008) Proximal tubule. In: Brenner BM (ed) The kidney, 8th edn. Saunders, Philadelphia, pp 39-50

Malmstrom K, Stange G, Murer H (1988) Intracellular cascades in the parathyroid-hormone-dependent regulation of $\mathrm{Na}+$ /phosphate cotransport in OK cells. Biochem J 251:207-213

Nielsen S, Kwon TH, Christensen BM, Promeneur D, Frokiaer J, Marples D (1999) Physiology and pathophysiology of renal aquaporins. J Am Soc Nephrol 10:647-663

O'Brien J, Wilson I, Orton T, Pognan F (2000) Investigation of the Alamar Blue (resazurin) fluorescent dye for the assessment of mammalian cell cytotoxicity. Eur J Biochem 267:5421-5426

O'Hare MJ, Bond J, Clarke C, Takeuchi Y, Atherton AJ, Berry C, Moody J, Silver AR, Davies DC, Alsop AE, Neville AM, Jat PS (2001) Conditional immortalization of freshly isolated human mammary fibroblasts and endothelial cells. Proc Natl Acad Sci USA 98:646-651

Racusen LC, Wilson PD, Hartz PA, Fivush BA, Burrow CR, Philip ET (1995) Renal proximal tubular epithelium from patients with nephropathic cystinosis - immortalized cell-lines as in-vitro model systems. Kidney Int 48:536-543

Racusen LC, Monteil C, Sgrignoli A, Lucskay M, Marouillat S, Rhim JG, Morin JP (1997) Cell lines with extended in vitro growth potential from human renal proximal tubule: characterization, response to inducers, and comparison with established cell lines. J Lab Clin Med 129:318-329

Reshkin SJ, Forgo J, Murer H (1990) Functional asymmetry of phosphate transport and its regulation in opossum kidney cells: phosphate transport. Pflügers Arch 416:554-560

Russel FG, Masereeuw R, van Aubel RA (2002) Molecular aspects of renal anionic drug transport. Annu Rev Physiol 64:563-594

Ryan MJ, Johnson G, Kirk J, Fuerstenberg SM, Zager RA, TorokStorb B (1994) HK-2: an immortalized proximal tubule epithelial cell line from normal adult human kidney. Kidney Int 45:48 57

Saleem MA, O'Hare MJ, Reiser J, Coward RJ, Inward CD, Farren T, Xing CY, Ni L, Mathieson PW, Mundel P (2002) A conditionally immortalized human podocyte cell line demonstrating nephrin and podocin expression. J Am Soc Nephrol 13:630-638

Satchell SC, Tasman CH, Singh A, Ni L, Geelen J, von Ruhland CJ, O'Hare MJ, Saleem MA, van den Heuvel LP, Mathieson PW (2006) Conditionally immortalized human glomerular endothelial cells expressing fenestrations in response to VEGF. Kidney Int 69:1633-1640

Stamps AC, Davies SC, Burman J, O'Hare MJ (1994) Analysis of proviral integration in human mammary epithelial cell lines immortalized by retroviral infection with a temperature-sensitive SV40 T-antigen construct. Int J Cancer 57:865-874

Terryn S, Jouret F, Vandenabeele F, Smolders I, Moreels M, Devuyst O, Steels P, Van KE (2007) A primary culture of mouse proximal tubular cells, established on collagen-coated membranes. Am J Physiol Renal Physiol 293:F476-F485

van Aubel RA, Smeets PH, Peters JG, Bindels RJ, Russel FG (2002) The MRP4/ABCC4 gene encodes a novel apical organic anion transporter in human kidney proximal tubules: putative efflux pump for urinary cAMP and cGMP. J Am Soc Nephrol 13:595-603

van de Water FM, Boleij JM, Peters JG, Russel FG, Masereeuw R (2007) Characterization of P-glycoprotein and multidrug resistance proteins in rat kidney and intestinal cell lines. Eur J Pharm Sci 30:36-44

Weiland C, Ahr HJ, Vohr HW, Ellinger-Ziegelbauer H (2007) Characterization of primary rat proximal tubular cells by gene expression analysis. Toxicol In Vitro 21:466-491

Wilmer MJG, Graaf-Hess A, Blom HJ, Dijkman HBPM, Monnens LA, van den Heuvel LP, Levtchenko EN (2005) Elevated oxidized glutathione in cystinotic proximal tubular epithelial cells. Biochem Biophys Res Commun 337:610-614

Yang YS, Balcarcel RR (2004) 96-well plate assay for sublethal metabolic activity. Assay Drug Dev Technol 2:353-361

Zhai XY, Nielsen R, Birn H, Drumm K, Mildenberger S, Freudinger R, Moestrup SK, Verroust PJ, Christensen EI, Gekle M (2000) Cubilinand megalin-mediated uptake of albumin in cultured proximal tubule cells of opossum kidney. Kidney Int 58:1523-1533 